\title{
Introduction of More Editorial Board Members and Journal of the American Board of Family Medicine's Position on the National Institutes of Health Public Access Policy
}

\section{Introducing JABFM Editorial Board Members: Larry Culpepper, Larry A. Green, and Howard K. Rabinowitz}

In an ongoing effort to acquaint our readers with the stellar cast making up the editorial board that advises and serves the Fournal of the American Board of Family Medicine, we are honored to introduce Larry Culpepper, Larry A. Green, and Howard K. Rabinowitz. Like James Mold, who was featured in January 2009, ${ }^{1}$ Drs. Culpepper, Green, and Rabinowitz are also members of the Institute of Medicine (IOM) of the National Academy of Sciences. The IOM's mission is to serve as adviser to the nation to improve health. The IOM provides independent, evidence-based, and authoritative information and advice concerning health and science policy to policy makers, professionals, leaders in every sector of society, and the public at large (http://www.iom.edu/CMS/AboutIOM.aspx).

\section{Larry Culpepper, MD, MPH}

Dr. Culpepper is the founding Chairman of the Department of Family Medicine at Boston University School of Medicine. He received his MD from Baylor College of Medicine and his MPH from Boston University. He is a past President of the North American Primary Care Group and formerly the Chairman of the Research Committee of the Society of Teachers of Family Medicine (STFM) and of the Board of Rhode Island Public Health Foundation. Dr. Culpepper was a Primary Care Fellow of the Federal Health Resources and Services Administration at the US Bureau of Health Professions and has chaired or served as a member of research grant review committees for 5 National Institutes of Health (NIH) and other federal agencies. He received the STFM Excellence in Education award and the STFM Curtis G. Hames Research Award honoring career contributions to family medicine research.

Dr. Culpepper has conducted research about otitis media and school-based and community interven-

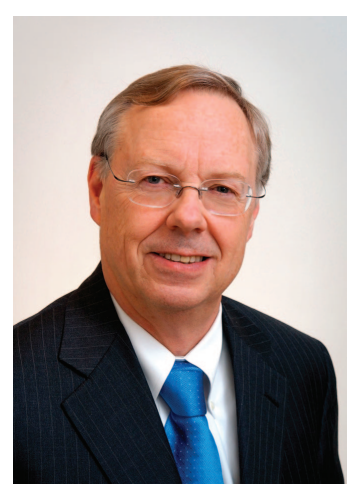

Larry Culpepper

tions to improve pregnancy outcomes and prevent teen pregnancies. He currently is the (1) principal investigator (PI) of the Agency for Healthcare Research and Quality-funded Center for Patient Safety Research, devoted to low income and minority vulnerable populations in ambulatory care settings; (2) the PI of a study about interventions to improve the care of uninsured patients and urban patients with diabetes and depression; (3) the co-PI of a study to decrease delays in community health center patient follow-up for abnormal mammography; and (4) coinvestigator on a study of the course of anxiety disorders in primary care settings. Dr Culpepper cochairs a panel on otitis media with effusion for the American Academy of Family Physicians, the American Academy of Pediatrics, and the American Academy of Otolaryngology-Head and Neck Surgery, and is a member of the American Academy of Pediatrics/ American Academy of Family Physicians panel on acute otitis media. He is also the family medicine editor of $U_{p}$ ToDate and the editor of the fournal of Clinical Psychiatry Primary Care Companion. Dr. Culpepper was elected to the IOM in 1998.

\section{Larry A. Green, MD}

Larry A. Green, MD, is Professor of Family Medicine and the Epperson-Zorn Chair for Innovation in Fam- 


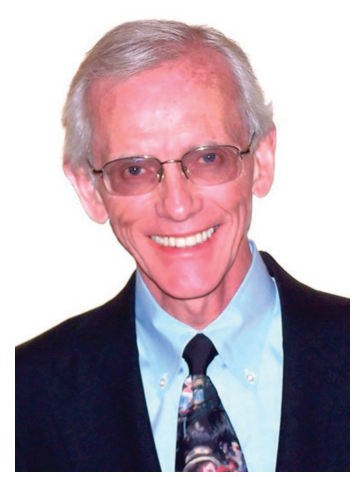

Larry A. Green

ily Medicine at the University of Colorado, Denver. After graduating from the Baylor College of Medicine and completing residency training at the University of Rochester he practiced medicine in the $\mathrm{Na}$ tional Health Service Corps before joining the faculty at the University of Colorado. He has remained a faculty member there throughout his career and has served in various roles, including practicing physician, residency program director, developer of practicebased research networks, and department chair.

In 1999, Dr Green became the founding director of the Robert Graham Center, a research policy center focused on family medicine sponsored by the American Academy of Family Physicians. He served on the Steering Committee of the Future of Family Medicine Project that propelled the patient-centered medical home forward, and also directed the Robert Wood Johnson Foundation's Prescription for Health national program focused on incorporating health behavior change in redesigned primary care practices. Dr. Green is a founding board member for Partnership 2040, a communitybased participatory research enterprise in the Denver area, and cochair of the Council overseeing the community engagement component of the Colorado Clinical Translational Sciences Institute. He currently is a member of the National Committee on Vital and Health Statistics and cochair of the Steering Committee for Preparing the Personal Physician for Practice, a national comparative case study of family medicine residency innovations. Dr. Green is chair-elect of the Board of Directors of the American Board of Family Medicine and was elected to the IOM in 1991.

\section{Howard K. Rabinowitz, MD}

Howard K. Rabinowitz, MD, is the Ellen M. and Dale W. Garber Professor of Family Medicine and

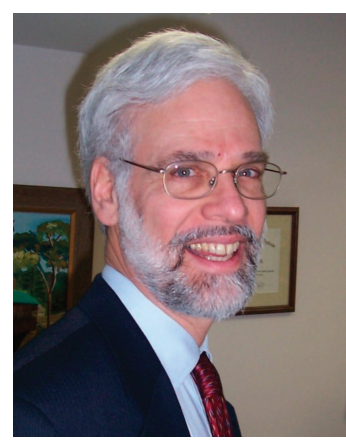

Howard K. Rabinowitz

Professor of Health Policy and Pediatrics at Jefferson Medical College of Thomas Jefferson University. Since 1976, he has served as Director of Jefferson's Physician Shortage Area Program, a special admissions and educational program that has been successful in increasing the supply and retention of family physicians in rural areas, as detailed in publications in the Fournal of the American Medical Association and The New England Fournal of Medicine. He also serves as Director of Jefferson's Family Medicine Research Fellowship.

Dr. Rabinowitz is a past-President of the American Board of Family Practice (1992 to 1993). From 1992 to 2000 he was a member of the National Advisory Committee of the Robert Wood Johnson Foundation's Generalist Physician Initiative. From 1993 to 1994, Dr Rabinowitz was a Robert Wood Johnson Health Policy Fellow in the Office of Senator John D. (Jay) Rockefeller IV (Democrat, West Virginia). He currently serves on the Robert Wood Johnson Foundation's Health Policy Fellowships Advisory Board. Dr. Rabinowitz is the recipient of the 2008 Curtis G. Hames Research Award. He was elected to the IOM in 2000.

Please look for other editorial board members' biographies in this section in subsequent issues.

\section{JABFMS Position on the NIH Public Access Policy}

The FABFM recognizes that as of April 7, 2008, all peer-reviewed publications reporting findings from studies funded by the NIH must be submitted to PubMed Central, the NIH's free digital archive of biomedical and life sciences journal literature in the United States. ${ }^{2}$ Per the NIH Public Access Policy, such NIH-funded publications must be made available no later than 12 months after the official date of publication. ${ }^{3}$

The $7 A B F M$ grants the author the right to provide a copy of the accepted, peer-reviewed version of the 
manuscript (ie, the final version that the author submitted through the Rapid Review System) to PubMed Central through the NIH Manuscript Submission system. This does not include the copyedited and formatted version used in the print and online publication, which may be a slightly updated version of the submitted manuscript because of corrections that may occur during the copyediting process. Authors are reminded that all manuscripts published by the $7 A B F M$ are protected by copyright through the American Board of Family Medicine. The 7ABFM requests that the manuscript submitted to PubMed Central be hyperlinked to the final online version published on the FABFM's website. Therefore, submissions to PubMed Central should not supersede FABFM publication dates.

As a courtesy to our authors, the $7 A B F M$ will submit a copy of the accepted, peer-reviewed version of the manuscript to PubMed Central if NIH funding is mentioned in the author-provided funding statement, but it is the author's responsibility to ensure that all NIH guidelines and policies are followed. The FABFM cannot place any guarantee on scholarly information submitted to PubMed Central.

Anne Victoria Neale, PhD, MPH

Marjorie A. Bowman, MD, MPA

Phillip Lupo, MLIS

\section{References}

1. Neale AV, Bowman MA, Lupo P. FABFM editorial board member's election to the Institute of Medicine and new journal alerts and features. J Am Board Fam Med 2009;22:4-5.

2. US National Institutes of Health. PubMed Central. Available at http://www.pubmedcentral.nih.gov/. Accessed 9 January 2009.

3. US Department of Health and Human Services. National Institutes of Health oublic access. NIH public access policy details. Available at http://publicaccess. nih.gov/policy.htm. Accessed 5 January 2009. 